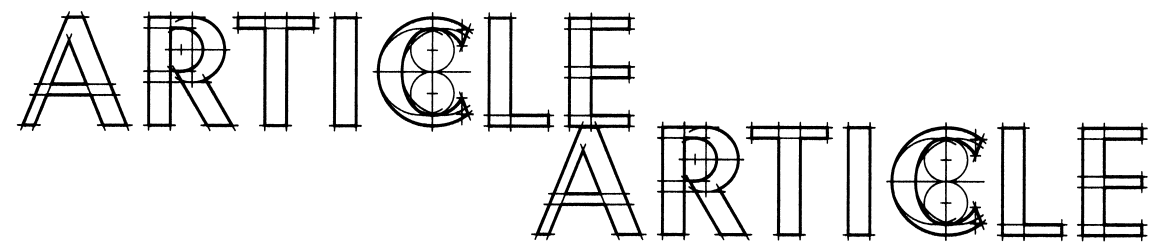

\title{
The End of the History of Optometry and the Beginning of a New One
}

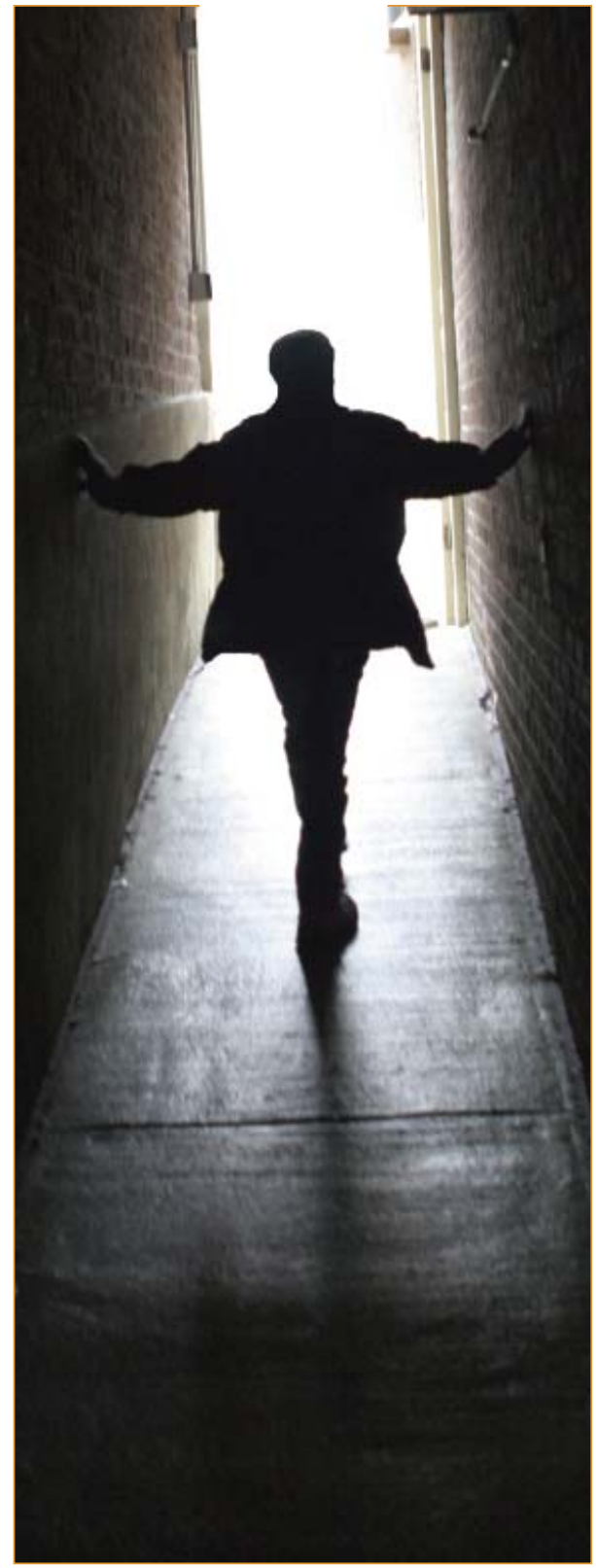

In Canada, the first legal use of the term "Optometry" was in 1909

Santos Tseng

OD, UW Class of 2004

PhD Student in

Vision Science

Clinical Optometrist

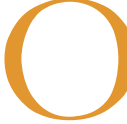

h, I'm not talking about the actual history. Beginning this September, OPTOM 100, the autobiographical course for our very own profession, will no longer be a part of the optometric curriculum at the University of Waterloo. No, the aptlynamed course is apparently slated for oblivion, forever stricken from the annals of Optometric education.

But how? Isn't that our history? Why would anyone think of doing away with that? Before any of us collectively rise in arms against this apparent injustice, an understanding of the reasoning behind this development might be in order.

The optometric landscape in Ontario is changing. The use of therapeutic pharmaceutical agents, virtually inconceivable even just ten years ago, is at the proverbial doorstep for the province's optometrists. With the change in scope comes a change in education. Given the need to include courses such as Immunology (OPTOM 134), Histology (OPTOM 108) and Human Gross Anatomy (OPTOM 124), there is apparently no room for the old course in the new curriculum. History of Optometry will thus be banished to history this upcoming fall. Gone, they say, with the wind.

Hmm. So, what will this change mean to those of us in practice? On the surface, it may 
not seem like a lot. A quick survey of my Class of 2004 peers produced the following:

\section{"It's about time?"}

"Good riddance?"

"It's not like we used any of it anyways?"

Indeed, the popular belief is that the elimination of History of Optometry is of little clinical consequence. Change, however, never occurs in a vacuum. Is the termination of OPTOM 100, therefore, a bellwether sign of change to come?

It has been suggested that as long as optometry continues to become more medically oriented, we risk losing elements of eye care that have defined our success in the past. Optometric graduates from yesteryear claim we don't dispense spectacles as well as we used to. We probably don't fit rigid lenses as well as we used to. With the binocular vision clinic at the School relegated to a few rooms on the second floor, we certainly don't do $\mathrm{BV}$ as well as we used to.

One could even argue that our bread-and-butter element, refraction, is a beleaguered entity these days. A quick perusal of the association website of our spectacle-dispensing brethren will show a handful of MPPs, and even a former Minister of Education endorsing the optician right to refract. Indeed, if change is what we are after, there are groups who are only too willing to give it to us.

Should we therefore be afraid of change? No. Change, they say, is a good thing. But before we embrace it, we must first understand it. But in order to understand it, we must first understand ourselves. Are we meeting the needs of our patients? Do we inspire confidence in them? What are we doing right? What can we be doing better? Is the current model of optometry sufficient, and if not, how can we improve? Does the evidence suggest a need for us to become more medically oriented?

Like an organism, our profession will evolve. But before we do, we should be sure of what it is we are evolving into, to ensure it is truly progress and not something else. Looking forward, each one of us optometrists will continue to make up and define this profession. We will all be oarsmen paddling the same ship. It is imperative that we also decide where it is we want it to go.

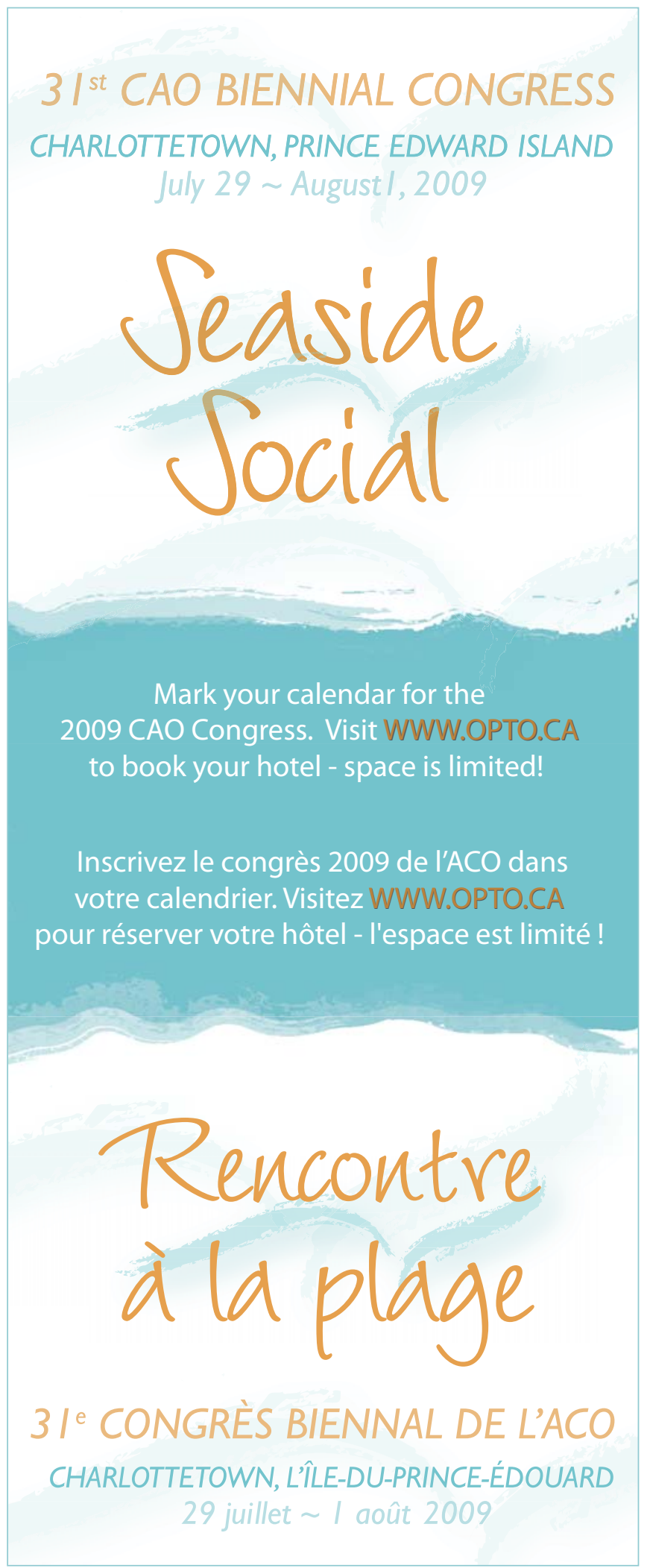

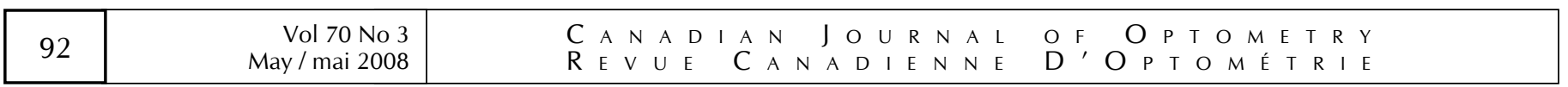

